\title{
Extraction of Lignin from Sugar Cane Bagasse and its Modification into a High Performance Dispersant for Pesticide Formulations
}

\author{
Zhili Li and Yuanyuan Ge* \\ School of Chemistry and Chemical Engineering and Guangxi Key Laboratory of Petrochemical \\ Resource Processing and Process Intensification Technology, Guangxi University, \\ 530004 Nanning, P. R. China
}

\begin{abstract}
Com o objetivo de utilizar efetivamente um sub-produto de material não madeireiro, foi extraída lignina do bagaço de cana-de-açúcar via acidificação do licor negro. A lignina extraída do bagaço da cana-de-açúcar (EBL) foi modificada por oxidação, hidroximetilação e sulfonação em um lignossulfonato solúvel em água (EBL-M). O composto foi caracterizado por IR, UV, GPC e análise elementar. Os resultados mostraram que as unidades aromáticas do EBL-M foram mantidas e efetivamente sulfonadas e que a porcentagem de $S$ foi alta $(7,82 \%)$. A eficiência de dispersão de EBL-M para formulações pesticidas foi comparada com dispersantes comerciais via medição da frequência de suspensão. Como esperado, EBL-M mostrou a mesma eficiência de outros lignossulfonatos comerciais para dispersar kinsperse, quando usados para grânulos de dimetomorfe dispersíveis em água. A caracterização através do peso molecular e do teor de lignossulfonatos no grupo sulfônico, sugeriu que a eficiência dispersante aumentou com o maior teor de grupo sulfônico e maior peso molecular. Quando usado para grânulos de tribenuron dispersíveis em água, a eficiência dispersante de EBL-M foi muito próxima dos dispersantes comerciais.
\end{abstract}

In order to effectively utilize a by-product of non-wood material, lignin was extracted from sugar cane bagasse via acidification of black liquor. The extracted sugar cane bagasse lignin (EBL) was modified by oxidation, hydroxymethylation, and sulfonation into a water-soluble lignosulfonate (EBL-M). It was characterized by IR, UV, GPC and elemental analysis. The results showed that the aromatic units of EBL-M were kept well and it was effectively sulfonated, that the percentage of $\mathrm{S}$ was high as $7.82 \%$. The dispersing efficiency of EBL-M for pesticide formulations was compared with commercial dispersants via suspending rate measurement. As expected, EBL-M had the equal optimal dispersing efficiency to kinsperse than other commercial lignosulfonates when being used for dimethomorph water dispersible granules. The characterization of molecular weight and sulfonic group's content of lignosulfonates suggested that the dispersing efficiency increased with higher sulfonic group's content and higher molecular weight. As to being used for tribenuron water dispersible granules, the dispersing efficiency of EBL-M was much close to the commercial dispersants.

Keywords: lignin, sugar cane bagasse, dispersant, pesticide formulation

\section{Introduction}

Biomass, which has the virtues of being abundant and being renewable, is the optimal sustainable resource for our industrial society. ${ }^{1}$ Especially, lignocellulosic biomass, as a nonedible biomass without affecting food supplies, has attracted scientific researchers around the world to develop technologies to convert it into fuels

*e-mail: geyy@gxu.edu.cn, zhilili@gxu.edu.cn and chemicals. The lower cost and faster growth of lignocellulosic biomass compared with food crops and its high availability make this resource an attractive raw material for substitution of fossil resources. ${ }^{2-4}$ Many of the procedures of papermaking, ${ }^{5}$ ethanol production and bio-oil synthesis ${ }^{6-8}$ consist of an acid hydrolysis process that has the drawback of producing a large amount of less reactive lignin as a by-product. Due to the poor water solubility of lignin, it is hard to use directly. Lignosulfonate, a derivative polyelectrolyte of lignin that 
has good water solubility and amphiphilicity, is widely used in many industrial applications, such as concrete, coal-water slurry, textile dyeing, agrochemicals and oil recovery processes, etc. ${ }^{9-11}$

However, in Asia and some places of the world where wood resources are less abundant, the utilization of nonwood plant materials such as straw, sugar cane bagasse and bamboo have been becoming increasing important. In South China, especially in Guangxi Province, sugar cane bagasse is an abundant natural solid lignocellulosic residue after extraction of juice from sugar cane stalk. A large amount of bagasse is currently burnt as a low-grade fuel for energy recovery; only a limited quantity has been used to make pulps, broad materials and composites. ${ }^{12-14}$ The expansive utilization of bagasse lignin is possible if its added value is enhanced, which is possible if industrial and scientific researchers can find better applications.

In this paper, we report some results on the utilization of sugar cane bagasse lignin based product for pesticide formulations. Lignin was first extracted from the black liquor of alkaline pulping of sugar cane bagasse, and then it was modified by oxidation, sulfonation and copolymerization, after which a water-soluble product was obtained. The dispersing efficiency of the product being used as a dispersant for pesticide formulations was estimated via suspending rate measurement and was compared with some commercial dispersants.

\section{Experimental}

\section{Extraction of lignin from sugar cane bagasse}

Lignin was extracted from sugar cane bagasse with an alkaline pulping process by a pulp and paper industry (Nanning Sugar Industry Co. Ltd., China). Lignin was precipitated from black liquor by acidification with sulphuric acid, until the $\mathrm{pH}$ of the solution was close to 2.0. Then followed by filtered and washed with distilled water until the $\mathrm{pH}$ of the rinse was close to 6.8. Finally, the extracted bagasse lignin was dried at $60{ }^{\circ} \mathrm{C}$ overnight, after which a fine powder was obtained (EBL).

The relative contents of moisture, ashes, and pure lignin content of EBL were measured as following. A certain amount of raw EBL was weighted and placed in an oven heated to $105^{\circ} \mathrm{C}$ in air. The corresponding mass loss was assigned as moisture. Another sample was placed in a muffle furnace heated to $800^{\circ} \mathrm{C}$ in air. The remaining amount was accounted as ashes. The pure lignin amount was subtracted the moisture and ashes from the total amount of sample. The properties of EBL are shown in Table 1.
Table 1. Properties of lignin extracted from sugar cane bagasse (EBL)

\begin{tabular}{ll}
\hline Properties & EBL \\
\hline Lignin source & Sugar cane bagasse pulping \\
Appearance & Light brown powder \\
Moisture / wt.\% & 5.2 \\
Ashes / wt.\% & 2.9 \\
Pure lignin / wt.\% & 91.9 \\
\hline
\end{tabular}

\section{Commercial lignosulfonates and other chemicals}

Commercial lignosulfonates (Borresperse, Ultrazine and Kinsperse) were purchased from Borregaard Lignotech., Norway. The active ingredients of pesticides (including dimethomorph and tribenuron) were obtained from Jiangsu Frey Agrochemicals Co. Ltd., China with a minimum purity of $95.0 \%$.

The other adjuvants for pesticide formulations are sodium dodecyl sulfonates (SDS), ethyl-naphthalene sulfonates, LH-14, LH-11, LH-AS and bentonite which were all purchased from Nanning Lantian Chemicals, China. Hydrogen peroxide solution (30\%) was also gained from Nanning Lantian Chemicals, China.

\section{Modification of the extracted sugar cane bagasse lignin}

A mixture of $10 \mathrm{~g}$ extracted sugar cane bagasse lignin (EBL) and $100 \mathrm{~mL}$ water was poured into a flask bottle equipped with an electric heating device, a motor stirrer, a thermometer, a dropping funnel, and a reflux condenser. The mixture was heated to $50{ }^{\circ} \mathrm{C}$ for 30 min and the $\mathrm{NaOH}$ solution was added to adjust the $\mathrm{pH}$ of the solution to 10.0. Subsequently, hydrogen peroxide was added dropwise to preoxidize EBL. The reaction was maintained 30 min and then formaldehyde was added dropwise for hydroxymethylation for $1 \mathrm{~h}$. After that the solution was heated to $85^{\circ} \mathrm{C}$ and $\mathrm{Na}_{2} \mathrm{SO}_{3}$ was added to cause sulfonation for $2 \mathrm{~h}$. Finally another part formaldehyde was added dropwise to copolymerize with the sulfonated EBL for $2 \mathrm{~h}$. The reaction mixture was cooled to ambient temperature and then was ultrafiltrated with a hollow fibre membrane, which had a 2500 molecular weight cut off to remove the inorganic reagents residues. The cutted fraction products were vacuum dried at $60^{\circ} \mathrm{C}$ overnight to yield a brown powder (EBL-M).

\section{FT-IR spectroscopy}

FT-IR spectroscopy was very often used to characterize lignin and lignin derivatives. ${ }^{15}$ The investigation of EBL-M by FT-IR spectroscopy was carried out on a Nexus 470 
FT-IR Spectrophotometer (Hewlett-Packard Development Company, L.P.). About $2 \mathrm{mg}$ of dried EBL-M was carefully mixed with $100 \mathrm{mg}$ of $\mathrm{KBr}$ and then was pressed into a flakelet. The spectrum was conducted between $4000 \mathrm{~cm}^{-1}$ and $400 \mathrm{~cm}^{-1}$ wavenumbers.

\section{Ultraviolet spectroscopy}

The ultraviolet spectroscopy of EBL-M was investigated by a UV-2501PC spectrophotometer (Shimadzu Corporation, Japan). The scan was conducted between $200 \mathrm{~nm}$ and $400 \mathrm{~nm}$ wavelength.

\section{Elemental analysis}

The elemental analysis was performed in Perkin Elmer PE 2400II apparatus, and the following elements were especially looked for: $\mathrm{C}, \mathrm{H}, \mathrm{O}, \mathrm{N}$, and S.

\section{Molecular weight distribution of EBL-M}

Molecular weight distribution of EBL-M was carried out with a Waters gel permeation chromatography (GPC) equipped with a 1515 HPLC pump, a 2478 dual absorbance detector with $0.1 \mathrm{~mol} \mathrm{~L}^{-1} \mathrm{NaOH}$ as eluent. Sodium polystyrene sulfonate was used as a standard sample (Sigma Aldrich). The injection volume of the sample was $20 \mu \mathrm{L}$.

\section{Determination of sulfonic group's content}

The sulfonic group's contents of lignosulfonates (EBL-M and commercial lignosulfonates) were measured by an automatic potentiometric titrator (809 Titrando, Metrohm AG., Switzerland). Lignosulfonate was firstly transformed into lignosulfonic acid by passing through anion exchange resin and cation exchange resin in turn. A certain volume of lignosulfonic acid $\left(\mathrm{V}_{1}\right)$ solution was titrated with $0.01 \mathrm{~mol} \mathrm{~L}^{-1} \mathrm{NaOH}$. The $\mathrm{pH}$ of the solution increased with increasing consumption of $\mathrm{NaOH}\left(\mathrm{V}_{2}\right)$ until the differential curve showed a distinctive mutation. The concentration of lignosulfonic acid $\left(\mathrm{C}_{1}, \mathrm{~g} \mathrm{~L}^{-1}\right)$ solution was determined by ultraviolet spectrophotometer. The sulfonic group's content was calculated by equation 1 :

$$
\mathrm{S}\left(\mathrm{mmolg}^{-1}\right)=\frac{0.01 \times \mathrm{V}_{2} \times 10^{3}}{\mathrm{~V}_{1} \times \mathrm{C}_{1}}
$$

\section{Preparation of water dispersible granules $(W G)$}

The $80 \%$ dimethomorph water dispersible granules (DWG) were prepared by a high-speed mixed granulation method. A mixture of $8.4 \mathrm{~g}$ dimethomorph (80 wt.\% active ingredient) and $0.8 \mathrm{~g}$ dispersant ( $8 \mathrm{wt} . \%$, EBL-M or the commercial lignosulfonates) and $0.8 \mathrm{~g}$ sodium dodecyl sulfonates and ethyl-naphthalene sulfonates were ground in a high speed mixer (Philip HR1727, Philips, Netherlands) for $5 \mathrm{~min}$. Then a total amount of 1.8-2.0 g of water was added in batches as a binder for granulation. After a continuous stirring, the formed granules between 20-40 standard meshes $(0.45-0.9 \mathrm{~mm})$ were dried as products. The detailed procedures were described in our previous work. ${ }^{16}$

The $75 \%$ tribenuron water dispersible granules (TWG) were also prepared by the procedures mentioned above. The compositions were as follow: $7.9 \mathrm{~g}$ of tribenuron (75 wt.\% active ingredient), $0.4 \mathrm{~g} \mathrm{LH}-14,0.3 \mathrm{~g}$ LH-11, $0.5 \mathrm{~g}$ dispersant (5 wt.\%, EBL-M or LH-AS), $0.9 \mathrm{~g}$ bentonite as carrier.

\section{Evaluation of dispersing efficiency}

Evaluation of the dispersing efficiency of lignosulfonates was indicated by the suspending rate of water dispersible granules that was conducted as follows. ${ }^{17}$ A required amount of water dispersible granules (active ingredient content: $m \mathrm{mg}$ ) was disintegrated in distilled water with shaking $2 \mathrm{~min}$ and then was put stationary for a certain time in a $250 \mathrm{~mL}$ graduated flask with a stopper. After that the upper $90 \%$ suspension was drew out and $10 \%$ suspension (active ingredient content: $q \mathrm{mg}$ ) was left. The contents of active ingredients of the WG and the left $10 \%$ suspension were determined by Agilent HPLC 1100 with a stainless column $(250 \mathrm{~mm} \times 4.6 \mathrm{~mm})$ packed by $\mathrm{C}_{18}$, with a mixture of methanol and water (v:v, 65:35) as mobile phase, injection volume of $20 \mu \mathrm{L}$, wavelength of $243 \mathrm{~nm} .{ }^{18}$ Thus the suspending rate of WG could be calculated by equation 2:

suspending rate $=\frac{10}{9} \times \frac{100(m-q)}{m} \%$

\section{Results and Discussion}

\section{FT-IR analysis of lignosulfonates}

The FT-IR spectrum of EBL-M was given in Figure 1. The fingerprint region lied between wavenumbers ranging from $700 \mathrm{~cm}^{-1}$ to $1600 \mathrm{~cm}^{-1}$ and typical stretching of chemical groups was observed at $2800 \mathrm{~cm}^{-1}$ to $3500 \mathrm{~cm}^{-1}$.

As shown in Figure 1, EBL-M presented all the expected functional groups of lignin derivatives. The adsorption bands at $1605 \mathrm{~cm}^{-1}$ and $1517 \mathrm{~cm}^{-1}$ were 


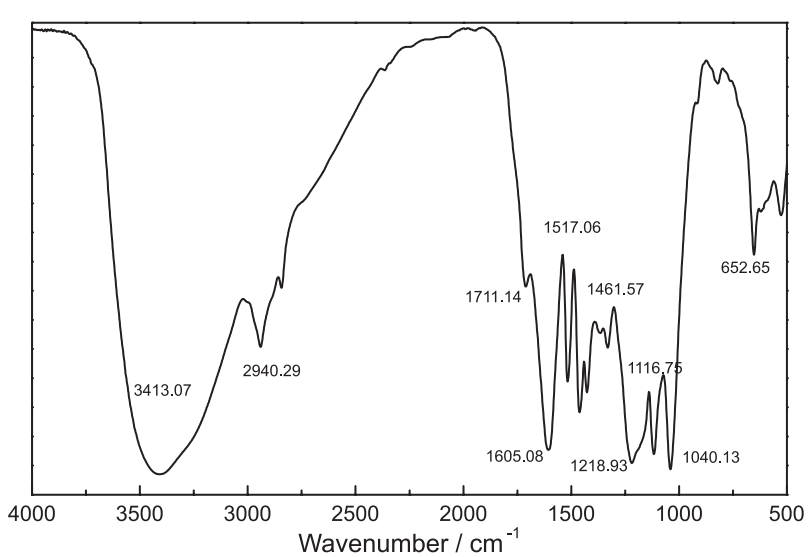

Figure 1. FT-IR spectrum of EBL-M.

characteristic of phenyl ring skeletal vibrations of lignin macromolecules. ${ }^{15,19}$ This observation confirmed that the core of lignin polymer did not change significantly during the extraction and modification procedures. The broad band at $3413 \mathrm{~cm}^{-1}$ was due to the presence of hydroxyls. The band at $2940 \mathrm{~cm}^{-1}$ was contributed to methylene and methyl groups. The adsorption of aromatic methoxy group was located at $2850 \mathrm{~cm}^{-1}$. The absorption at $1711 \mathrm{~cm}^{-1}$ was characteristic for the presence of an aldehyde or ketone carbonyl group. As to the fingerprint region: the vibration of methylene and methyl groups were at $1461 \mathrm{~cm}^{-1}$ and $1420 \mathrm{~cm}^{-1}$, and methyl groups also at $1375 \mathrm{~cm}^{-1}$, methylenes and hydroxyls at $1330 \mathrm{~cm}^{-1}$ and aromatic rings near $850 \mathrm{~cm}^{-1}$. The $\mathrm{C}-\mathrm{O}$ bonds were considered at $1260 \mathrm{~cm}^{-1}, 1219 \mathrm{~cm}^{-1}$. The band at $1040 \mathrm{~cm}^{-1}$ was duo to the $-\mathrm{SO}_{3}$ adsorption.

\section{Ultraviolet spectrum of EBL-M}

Figure 2 showed the ultraviolet spectrum of EBL-M. It presented a typical adsorption peak near $280 \mathrm{~nm}$ (due to phenolic groups), a shoulder at $230 \mathrm{~nm}$ and a maximum adsorption at $200-208 \mathrm{~nm}$ (assigned to conjugated $\mathrm{C}=\mathrm{C}$ ). The typical adsorption peak at $c a .280 \mathrm{~nm}$ shifted to a

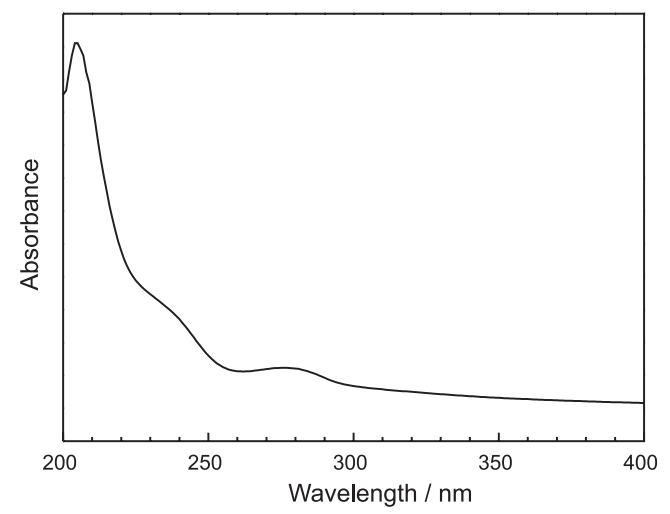

Figure 2. Ultraviolet spectrum of EBL-M. shorter wavelength at $276 \mathrm{~nm}$, which indicated the sugar cane bagasse lignin contained much more symmetrical syringyl units than guaiacyl units and $p$-hydroxyphenyl units. $^{19}$

\section{Elemental analysis of EBL and EBL-M}

As represented in Table 2, the contents of $\mathrm{C}$ and $\mathrm{N}$ of EBL were decreased by comparing with EBL-M. This could be due to the elimination of organic impurities (such as protein) by the oxidation process. ${ }^{20}$ The percentages of $\mathrm{H}$ and $\mathrm{O}$ were in close agreement for EBL and EBL-M. The content the content of $\mathrm{S}$ was clearly increased, which was caused by the sulfonation process.

Table 2. Elemental analysis

\begin{tabular}{lccccc}
\hline & $\mathrm{C} \%$ & $\mathrm{H} \%$ & $\mathrm{O} \%$ & $\mathrm{~N} \%$ & $\mathrm{~S} \%$ \\
\hline EBL & 58.75 & 5.89 & 31.92 & 2.65 & 0.78 \\
EBL-M & 52.86 & 5.75 & 32.39 & 1.17 & 7.82 \\
\hline
\end{tabular}

Molecular weight distribution and sulfonic group's content of $E B L-M$

The molecular weight distribution of EBL-M was measured by GPC. As shown in Figure 3, it had a standard normal distribution. Weight- and number-average molecular weights $\left(M_{w}\right.$ and $M_{n}$, respectively) as well as polydispersity $\left(\mathrm{M}_{\mathrm{w}} / \mathrm{M}_{\mathrm{n}}\right)$ of EBL-M were presented in Table 3. The sulfonic group's content of EBL-M measured by titration are also in Table 3. For comparison, the values of the commercial lignosulfonates reported by our previous work ${ }^{21}$ were also listed in Table 3.

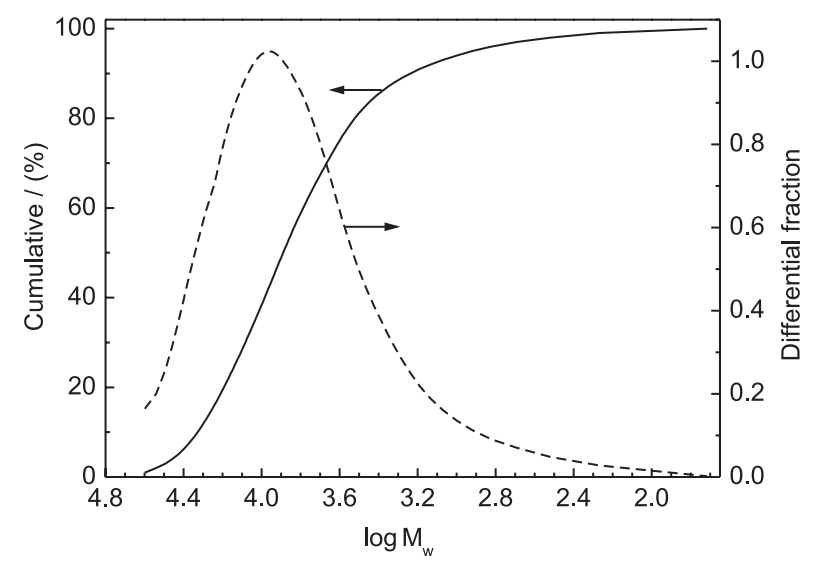

Figure 3. Molecular weight distribution of EBL-M.

Table 3 showed that EBL-M had the largest weightaverage molecular weight (8600). Kinsperse had the highest sulfonic group's content $\left(2.05 \mathrm{mmol} \mathrm{g}^{-1}\right)$ and 
Table 3. Properties of EBL-M and commercial lignosulfonates

\begin{tabular}{lcccc}
\hline lignosulfonates & $\mathrm{M}_{\mathrm{w}}$ & $\mathrm{M}_{\mathrm{n}}$ & $\mathrm{M}_{\mathrm{w}} / \mathrm{M}_{\mathrm{n}}$ & sulfonic group's content / (mmol g-1) \\
\hline EBL-M & 8600 & 2900 & 2.97 & 1.86 \\
Kinsperse & 5200 & 1200 & 4.33 & 2.05 \\
Borresperse & 7100 & 2700 & 2.63 & 1.20 \\
Ultrazine & 5500 & 2000 & 2.75 & 1.36 \\
\hline
\end{tabular}

EBL-M had the second highest sulfonic group's content $\left(1.86 \mathrm{mmol} \mathrm{g}^{-1}\right)$.

\section{Dispersing efficiency of EBL-M for pesticide formulations}

In this experiment, dispersing efficiency of lignosulfonates was determined by the suspending rate measurement of dimethomorph water dispersible granules (DWG) in the presence of different lignosulfonates additives. It was well-known that the suspending rate of water dispersible granules was related to the content of dispersant. ${ }^{22}$ The relationship between the suspending rate and dosage of lignosulfonate (Kinsperse) was presented in Figure 4. As shown, the suspending rate of DWG with kinsperse increased with an increase of the dosage of kinsperse. The suspending rate of DWG reached a plateau at $8.0 \%$ dosage. Thus, we evaluated the dispersing efficiency of lignosulfonates by measuring the suspending rate at $8.0 \%$ added to the pesticide formulation.

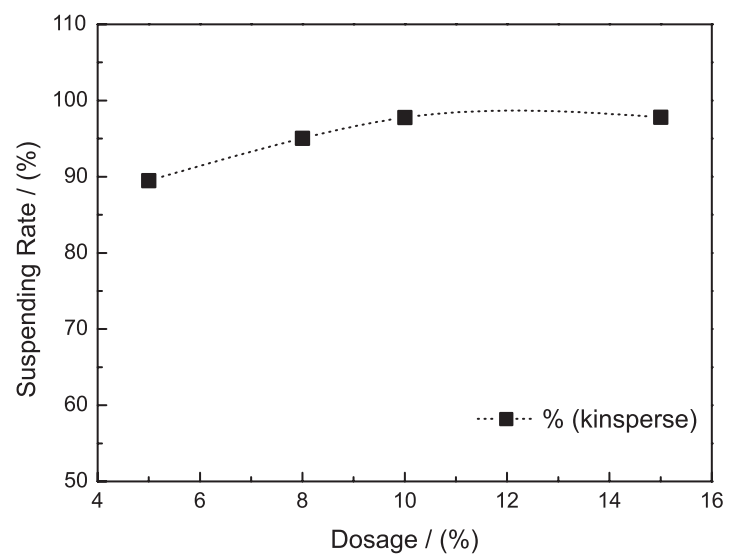

Figure 4. Suspending rate of DWG using kinsperse as dispersant.

The suspending rates of DWG using EBL-M and commercial lignosulfonates as dispersants were shown in Figure 5. It was found that kinsperse and EBL-M had the higher dispersing efficiency than other commercial lignosulfonates. The efficiency could be explained in two aspects: (i) higher molecular weight of lignosulfonate had a larger steric repulsive force, and (ii) higher sulfonic group's content of lignosulfonate had a stronger electrostatic repulsive force. ${ }^{23}$ In addition, the dispersing efficiency

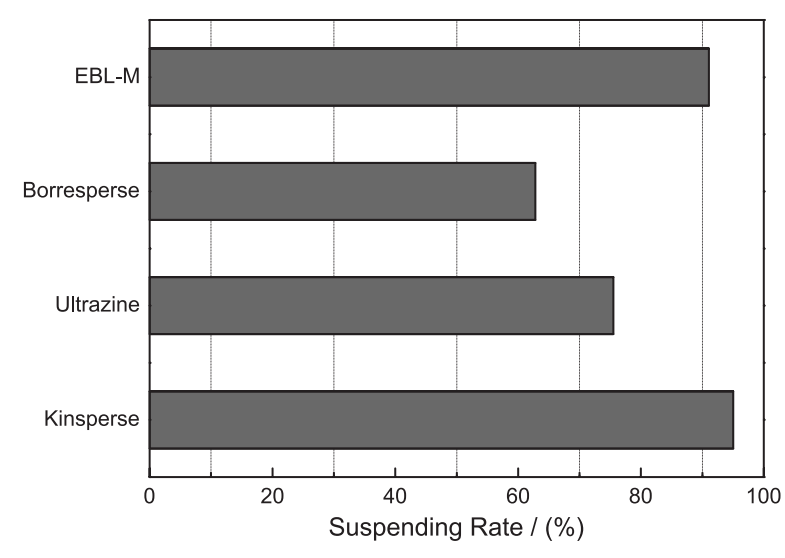

Figure 5. Suspending rate of DWG with different lignosulfonates at $8.0 \%$ dosage.

of EBL-M was less than kinsperse, which indicated the electrostatic repulsive force was premier to steric repulsive force in this aqueous dispersing system. The similar conclusion could be drawn by the comparison of ultrazine with borresperse.

EBL-M was also used as a dispersant for producing $75 \%$ tribenuron water dispersible granules (TWG). The suspending rates of TWG were also measured for investigating its dispersing efficiency comparing with a sodium polyacrylate dispersing agent ${ }^{24}$ and a commercial dispersant (LH-AS) ${ }^{25}$ The suspending rates of TWG were shown in Figure 6. It presented that the suspending rate of TWG with different dispersants were closed with each other and were all above $90 \%$, indicating that EBL-M

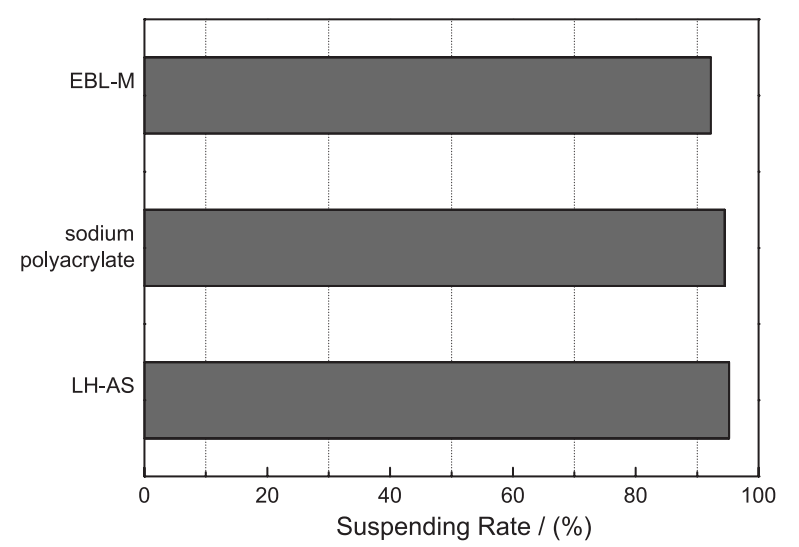

Figure 6. Suspending rate of TWG with different lignosulfonates. 
had high dispersing efficiency for $75 \%$ tribenuron water dispersible granules.

\section{Conclusions}

Lignin was extracted from sugar cane bagasse via acidification of black liquor. The extracted lignin (EBL) was modified by oxidation, sulfonation and copolymerization into a lignosulfonate (EBL-M), which was characterized by FT-IR, UV, elemental analysis, GPC, and titration to determine the molecular structure and sulfonic group's content. UV spectrum indicated the molecules of EBL-M contained more symmetrical syringyl units than guaiacyl units and $p$-hydroxyphenyl units. FT-IR spectroscopy revealed that the aromatic units were kept during the extraction and modification procedures. Elemental analysis represented that the content of S of EBL-M was much higher than EBL. Titration results showed the sulfonic group's content of EBL-M was $1.86 \mathrm{mmol} \mathrm{g}^{-1}$ being close to kinsperse and the $M_{w}$ were 8600 being higher than all commercial lignosulfonates.

To estimate the dispersing efficiency of lignosulfonates for pesticide formulations, suspending rate measurement was conducted. It was found that EBL-M had the equal optimal dispersing efficiency to kinsperse than other commercial lignosulfonates when being used for dimethomorph water dispersible granules. By the combination of molecular weight and sulfonic group's content measurements, there was a conclusion that the dispersing efficiency increased with higher sulfonic group's content and molecular weight. Especially higher sulfonic group's content played a more important role on it. As to tribenuron water dispersible granules, the dispersing efficiency of EBL-M was much close to the sodium polyacrylate dispersing agent and LH-AS.

\section{Acknowledgments}

The authors wish to thank the supports of Guangxi University Natural Science Foundation (XB2090782).

\section{References}

1. Chheda, J.; Huber, G. W.; Dumesic, J. A.; Angew. Chem., Int. Ed. 2007, 46, 7164.

2. Klass, D. L.; Biomass for Renewable Energy and Fuels; Elsevier: London, 2004.
3. Huber, G. W.; Iborra, S.; Corma, A.; Chem. Rev. 2006, 106, 4044.

4. Lange, J. P.; Biofuels, Bioprod. Biorefin. 2007, 1, 39.

5. Coelho, D.; Marques, G.; Gutiérrez, A.; Silvestre, A. J. D.; Río, J. C. d.; Ind. Crop. Prod. 2007, 26, 229.

6. Aden, A.; Ruth, M.; Ibsen, K.; Jechura, J.; Neeves, K.; NREL Rep. TP-510-32438. U.S. Natl. Renew. Energy Lab. 2002; http:// www.osti.gov/energycitations/servlets/purl/15001119-zb17aV/ native/.

7. Kumar, P.; Barrett, D. M.; Delwiche, M. J.; Stroeve, P.; Ind. Eng. Chem. Res. 2009, 48, 3713.

8. Sun, Y.; Cheng, J.; Bioresour. Technol. 2002, 83, 1.

9. Martins, G.; Vara, E.; Duarte, C.; Ind. Crop. Prod. 2008, 27, 189.

10. Stewart, D.; Ind. Crop. Prod. 2008, 27, 202.

11. Lora, J. H.; Glasser, W. G.; J. Polym. Environ. 2002, 10, 39.

12. Paiva, J. M. F.; Frollini, E.; J. Appl. Polym. Sci. 2002, 83, 880.

13. Stael, G. C.; Tavares, M. I. B.; Almeida, J. R.; Polym. Test. 2001, 20,869 .

14. Zarate, C. N.; Aranguren, M. I.; Reboredo, M. M.; J. Appl. Polym. Sci. 2000, 77, 1832.

15. Fengel, D.; Wegener, G.; Wood-Chemistry, Ultrastructure, Reactions; Walter de Gruyter: Berlin, 1989.

16. Li, Z.; Qiu, X.; Pang, Y.; Ouyang, X.; Lou, H.; Journal of Chemical Engineering of Chinese Universities 2009, 23, 466.

17. Ling, S. H.; Solid Formulation, $3^{\text {rd }}$ ed.; Chemical Industry Press: Beijing, China, 2003.

18. Yang, J.; Huang, C.; Xiong, L.; Fine Chemical Intermediates 2003, 33, 50 .

19. Hergert, H. L.; Lignins, Occussence, Formation, Structure, and Reactions; Wiley Interscience: New York, 1971.

20. Gosselink, R. J. A.; Abächerli, A.; Semke, H.; Malherbe, R.; Käuper, P.; Nadif, A.; Dam, J. E. G.; Ind. Crop.Prod. 2004, 19, 271.

21. Li, Z.; Pang, Y.; Li, X.; Qiu, X.; J. Chem. Ind. Eng. 2008, 59, 2127.

22. Bell, G. A.; Water-Dispersible Granules, $4^{\text {th }}$ ed.; Kluwer Academic Publishers: London, 1998.

23. Myers, D.; Surfactant Science and Technology, $3^{\text {rd }}$ ed.; John Wiley \& Sons, Inc.: Hoboken, New Jersey, 2006.

24. Li, H.; Zhang, Q.; Xu, Y.; Jiao, Q.; Agrochemicals 2006, 45, 253.

25. Li, W.; Lai, H.; Ge, Z.; Ding, C.; Zhou, Y.; Journal of Zhejiang University fo Technology 2006, 34, 154.

Submitted: March 3, 2011 Published online: July 19, 2011 